\title{
Museology as a Discipline OF INFORMATION SCIENCES
}

\author{
Ivo Maroeviç
}

Museology, like any other generalist academic discipline, has originated, developed and assumed forms which are in fact the most appropriate for its development. It is certainly not a basic academic discipline, but it has developed at an information level which is partly based on the results of research in other basic disciplines and partly follows the epistemology of the information sciences. It does not function on the level of applied sciences. It functions at a conceptual level which is different from that of the basic disciplines. Museology, like any discipline belonging to such a category, develops from practice and is confirmed in practice. It also anticipates practice, but it deals too with the theoretical study of those phenomena which will manifest themselves in practice. So museology is unseparable from practice.

The inclusion of museology in the field of information sciences opens up a new conceptual level, but also implies certain limitations. Such limitations are part of the approach, because museology with its wide social significance does not deal only (though it mostly does in fact) with the study of museality through the material world, or as Peter van Mensch says with the musealization of objects which become musealia (museum objects). By studying the museality of objects, as well as musealization (the process in which objects gradually become musealia), we are still at all times at the level of isolated or alienated heritage. The social relation of "protection of heritage» demands integrity with the context. It demands museality not only in the sense of isolation within a museum reality, but also the transmission of messages about the properties of the heritage within the vital context of man. This implies all those dangers which threaten the object itself as well as the context, and the characteristic features of the object when it finds itselves in a place exposed to all the winds of reality in the present. The present is dynamic and offers no special protection within a museum reality.

Very often the museology will observe an object not only as a carrier or source of information, but also as an emitter within a communication process or as a document of one of the possible realities. Finally museology should observe a museum object also as a variable which contributes 
78 to the enrichment of the human environment, which plays a part in creating various identities and affects life in its entirety. Bearing such features, museology will widen the theoretical core of information sciences, and will bring about a greater appreciation of cultural information and of its features such as multi-layering, changeability, and influence on the entire life of mankind.

The relatively well defined methodology of information sciences, applied with modification to museology, will help museology to systematically define its tasks and research objectives. In comparison with library and archival science, lexicology and other related branches of the information sciences, we can see that museology has specific features because the object of its research - the object of heritage (or musealia in a narrower sense) - is at all times a part of reality, not as yet transmitted to another medium. A book, a charter or any other written document is a certain abstraction in relation to reality (this is not to say that at a certain moment they cannot become the object of heritage). In order to be able to decode the information inherent in a museum object, one needs to read the language of the object (its form, material and structure) for which the basic academic disciplines such as archaeology, ethnology, history of art, natural sciences, etc. should prove helpful. On the other side the language of objects and contexts can be more direct, more complete and more meaningful than the verbal language of written documents. The results of the communication achieved using such language are transformed to human knowledge only by formalizing them into language understood by all and as unified as possi- ble for transference and dissemination. Only recorded data or information can be entered into classical information-documentation systems. Only then can museology be seen as equal to other branches of the information science.

The museum object as a document of a certain reality, a basis of identity, a witness of events, a result of man's skill or a product of nature, the evidence needed to back up many claims and scientific theses within the framework of various basic academic disciplines, is without doubt an element of the information basis of human knowledge. As such, it is the subject matter of museology. Museology should define its theoretical foundations for the formulation of a system for selecting, identifying and collecting such objects into museum collective funds, as well as a system for the protection, study, documentation and dissemination of the created data. Finally, this should also apply to the system of interpretation, communication and the creation of artificial entities, as well as the improvement of existing contextual entities within the museum or any other reality. Thus, we have very concisely defined the framework of museology as an academic discipline.

\section{MUSEOLOGY AND MUSEUM PRACTICE}

The integration of museology with the museum practice and the protection of cultural and natural heritage varies considerably from country to country. It is necessary to establish a few assumptions which should be realised as preconditions for a full integration of museology and practice. First of all, the museum staff 
should accept museology as a discipline which deals theoretically with the activity in which they are participants. Then, they should have the ability to absorb theoretical ideas and a willingness to apply them in practice. This is a necessary precondition for the success of any communication process. It also implies confidence in being able to solve certain practical problems with the help of theoretical ideas. When these assumptions are met, the possibility of communication between theoretical statements being transmitted (primarily through publications, professional periodicals, expert missions and training programmes) and those who should receive and transform them into practical solutions will be realized.

The basic quality of the museological concept is realised at the structural level. The reason for this is the fact that the techniques and technology applied in museum work are applied when this activity exists and when it is ideologically determined. Then all practical museographical achievements are put at the service of ideas. The defining of such an idea is the subject matter of museology, and it is impossible to offer recipes for it.

Museology, which opens up wide perspectives of context, permeation of meanings, variability of meanings of museum objects, their many-sided applicability, expands the museum reality beyond the defined museum space to human life, to the everyday future, but it remains nevertheless a very abstract phenomenon if we consider it from the aspect of providing instructions and manuals for its application. Theoretical museological thought should open up views, widen the horizon and break through the frameworks and limitations of ancient prejudices. Its ideas within the function of man and society, because only thus can they save the heritage (in the totality of all its meanings) for the future in the active present. I wish to point out the importance of that variable of the present, which is dynamic and which always moves with each stroke of the clock, with each flicker of the eye, with each digital impulse, in relation to the stable past which is constantly expanding and the future which is constantly diminishing. The grammatical difficulties of languages with the dynamics and perfectiveness of expressing the present are not accidental.

Museology must open up theoretical space for exploiting the present in the function of the past (protection) and of the future (improvement of human life). The comprehensive dynamic of change in space and the environment around us has to be realised in the museum setting. The museum of the future will be a museum of everyday modifications of meanings, without regard for possible constants. The defect of the museum of the past lies in the sphere of ideas, in its attempts to stop time, to be analytically halted in a period about which we create an image of a certain different time. Museographical techniques and technology have been directed to the conservation of time in the museum. The conservatism of museums (as institutions) and their position within different societies is based on this fact.

The new museological concept should aspire to open up theoretical perspectives in which the tension between material and time could eventually be overcome. Is it knowledge or information that constitute 
the new concept? In either case a new museology cannot give instructions, nor institutionalize its thoughts and ideas. It should and can create a spiritual and contemplative atmosphere. It should always leave open space for searching, for attempts, for new concepts. It must not sever its ties with tradition, and to paraphrase Tomislav Sola, it must make possible the gradual transformation from representative museums to those which represent human beings, time, the context of human life and knowledge (Sola 1980). Such a reflective basis, which will develop its own theoretical and methodological core and which today can perhaps combine with the information inherent in wide information and communication processes, should furthermore find its place within the framework of possible human thought and the scholarly world. This place will enable the objects of heritage, which we select from reality, to create a further reality which will in turn humanize the life of those who are yet to come, as well as creating a more dynamic context for heritage, a context in which heritage will not be a traditional burden but the framework for a more creative life. The heritage which cannot to be separated from reality could use the same ideas to develop its own interpretation and protection with the same aim. Therein lies the width of museological thought, its potential and its place in the heritage theory.

\section{THEORETICAL POSSIBILITIES}

Museological theory is the structural level on which a system of abstract thought concerning museology can be formed. It provides a basis for scientific understanding, and a methodological approach to the scholarly discipline of museology. Replies to the basic questions as to what museology is, where its field of interest lies, upon what theoretical assumptions it operates, how relations between theory and practice are adjusted - all these find an answer in museological theory. Man's heritage, his meaningful relationships in it and its place in his life are the essence of museology. They are a stimulus to inter-disciplinary work with other fields of scholarship which approach the human heritage from a different analytical angle. They will stimulate the development of museology within information sciences and it will be essential to explore the variations of identification and communication of meanings and information inherent in the world heritage which surrounds us. This information is concentrated on Man within the cultural context, and on life enriched by his cultural heritage. The span of theoretical possibilities is wide.

Museology is the area of information sciences concerned with research into, identification, preservation and communication of the museality of the material manifestations of culture and nature (in the first place musealia) in order to preserve human heritage and interpret and transmit its significance. It is concerned also with forms of organized and institutionalized human activity (especially museums) serving the above goals.

Museology deals with the systematic study of the process of emitting information stored or concealed within the material structure of heritage objects (or musealia) and of decreasing the field of museal indefiniteness of any particular musealia, collection or the museal system. It con- 
stantly deals with theoretical and practical questions of identifying museality. Furthermore, on various communication levels museology is involved in establishing links between musealia (with variable quantities of information among which material messages are stable and social ones variable, depending on the interpretation of data) and experts, the environment and potential users. It thus makes possible the transmission, dissemination, explanation and use of information intrinsic to heritage objects or musealia, allowing it to be realized by selection, collection, evaluation, scientific and professional elaboration, protection, storage, display and editing of such objects. Museology operates through museum publications, the formation of museum collections and collective funds and through permanent and temporary exhibitions. Such heritage objects and musealia are the documents of authentic reality and the creators of museum reality. They emit inherited information and very often, in the form of complex information structures, transmit messages to users who set up the communication relationship.

\section{MUSEALIA: COMMUNI- CATION OBJECTS}

Musealia, the carriers of information, are stored and preserved in museum collections. Every object or complex of the human heritage, especially musealia, is an explicit communication object which in relation to the society and place in which it lives develops an information process. In relation to society and time it develops a communication process and in relation to time and space it develops a documen- tation process. In this sense museology as the storage and protection of information but also with social communication, and the exchange of messages between past and present, the developed and the developing world, between human beings of various social structures and status, between nature and man. This communication can be achieved through musealia which have the potential to emit an unlimited amount of information, and complex information structures while at the same time retaining their documentary character.

Neither information theory, nor a detailed selection of facts, (mechanical, automatic or electronic) can free museological institutions (primarily museums) from the duty and necessity of interpretation. Nor can special criteria free museums from their responsibility to collect, evaluate, preserve, study and exhibit musealia.

The limitations of those who are receiving information from objects in museum holdings or from items in the heritage itself are considerable. This is why some aspects of museology must be concentrated on devising ways to educate recipients, and with levels of information transmission. This will allow communication to be as full and as immediate as possible. For this reason the training of a museologist must include a thorough understanding of the information sciences and a full mastery of those areas which are concerned with research in various aspects of the world heritage and information potential. The information that musealia carry is not expressed (or very seldom) in any one of the conventional languages (natural or artificial) and therefore entails training in the understanding of objects from the 
82 natural world, recording them in the conventional manner in the greatest possible detail and training professional staff to be able to read information emitted from museum items and to identify the museality in the objects. This is as important as an understanding of information methods and approaches and will allow museum staff to identify information and transmit it adequately to the visitor who is the final recipient of information.

\section{WIDER HORIZONS FOR MUSEOLOGY}

Being a generalist discipline, primarily interdisciplinary, museology allows the integration and interpretation of human activities. The social, humanist and natural sciences touch aspects of special museology. Thus museology can be smoothly integrated into information sciences. On the other hand museum collections or complexes of man's heritage cannot be approached like a normal data bank. Museological research and presentation are more complex. Information can seldom be presented in an elementary form as in the standard IN-DOC system.

Cultural objects and heritage ensembles, like musealia, are rich in structural information conditioned by our social and cultural being. These are often part of the very essence or museality of an object and become an actual message only in a given context. It is impossible to select information of this kind because it emerges or disappears depending on the value systems according to which it is structured (ethical, aesthetic, political etc.). When they are noted together with context and structural system, then they can be slowly transposed into the circle of selective information (Tudjman 1983:96-101). Most of the scientific information carried by musealia has selective characteristics and is marked by the criteria of truthfulness and ethical neutrality and is not overdependent on context. When scientific information, which is often the case with museum objects, is used in the service of a cultural message, it then obtains to a greater or lesser extent the character of structural information, because its truthfulness and ethical neutrality are superseded by a situation in which context provides new meaning. Research into the communication patterns through which the structural information within musealia may be transmitted provides wide possibilities for the development of specific museological theories within the accepted limits which musealia carry as part of their material substance and meaning, and which set the range and difference between actual and museum reality and make it possible, through knowledge of the totality of a museum collection, to decipher the various levels of structural information and distinguish structural from scientific information within individual objects (musealia), cultural heritage ensembles, or collections of objects.

Only the recorded data or information transmitted by musealia can be included in the ordinary IN-DOC system. They then obtain and carry all the characteristics of selective information. Research according to formalized rules is then possible within a precisely selected field of interest.

The inconstancy of social forms of messages, the influence of interpretation and the varying aspects of observation yielded 
by different communication patterns, require that museology, information science in the narrower sense, communicology and other disciplines of the information sciences should take into account this specificity so that individual items and cultural heritage ensembles, the totality of the museum collection and musealia which carry the information, are given as qualitative a theoretical basis as possible and become firmly integrated into the total system of human knowledge. It is here that the perspectives for museology lie, instead of continuing to be stretched as now, between the specific nature of its own subject and the methods which it uses, and other basic academic disciplines which are concerned with research into objects and cultural heritage complexes, but not with the problems of their museality.

Linkage with the integrated field of information sciences and formal separation from the basic social, humanist and natural sciences with which museology was so often confused in the past, and sometimes even today, will open up far wider horizons for museology as an academic discipline. Its field of activity will be more precisely defined, and methodologically it will be able to expand still beyond the bounds set by those academic disciplines which until now have only been concerned with researching items of the cultural heritage.

The kernel of the definition of information sciences shows that cultural information is still not on a completely equal footing with other forms of information and that structural information is only just beginning to become apparent in some parts of the field, while the passing of time has shown that some disciplines of information science such as museology, archivistics, library science and documentation science have achieved independent status. The pressure of single-strata, routine and scientific information, restricted by the language of verbal and digital data, is increasingly leaving the door wide open for structural and cultural information, part of the information is concealed in museum objects which are the origin and form the basis of the non-conventional message. It is here that the chance lies for museology to help in the creation and presentation of a knowledge.

\section{OBJECTS AS CARRIERS OF MUSEALITY}

According to Z.Z. Stransky museality is the intrinsic characteristic of a museum item. "Museality is that aspect of reality which we can know only through a presentation of the relationship between man and reality" (Stransky 1970:35). In other words museality is the characteristic of something that in one reality documents another reality, in the present it is a document of the past, in a museum a document of the real world, within one space is the document of other spatial relations. Material and form are carriers of museality. An object in a museum is a carrier of museality, this is what Stransky calls musealia. Its characteristic is that in a different museal reality it is taken to document the reality it originally belonged to, which was distinguished by place, time and society so that the item may therefore be regarded as documenting place, time or society. These three terms of reference may be synchronic or asynchronic or a 
84 combination of the two. Thus objects from one place and time may be documents of different societies if they are witnesses of such. Objects of a fixed place may document the time of their origin or the passage of time and the social status which they represented. A worn or discarded object may document the time and place to which it belonged, or some moment of a time of which only tenuous indications still exist of its former importance.

Museality is most obvious in objects which are musealized or in surroundings which are completely or partly musealized in the sense of an active communication and interpretation of their documentary or other values. Examples, in addition to various kinds of museums, are churches and castles that are conserved and open to the public, archeological sites and ruins, historic cities with interpretative signs, or villages arranged like open-air museums, nature parks, botanical gardens and zoos. But museality is present too in everyday articles in which people can find links with the past fragments of time and place which have been preserved, and to anyone who manages to make meaningful contact with them they speak of the society from which they originally came, of the people of that time, and the place where they arose. These are not museum items, but they have a museality that continues to live around us, and which forms the heritage of the circle of people who understand them. They are part of the culture of the emotions, and they carry hidden messages of times gone by.

Considered globally the heritage will not shrink, for the passing of time will continually create new cultures from the

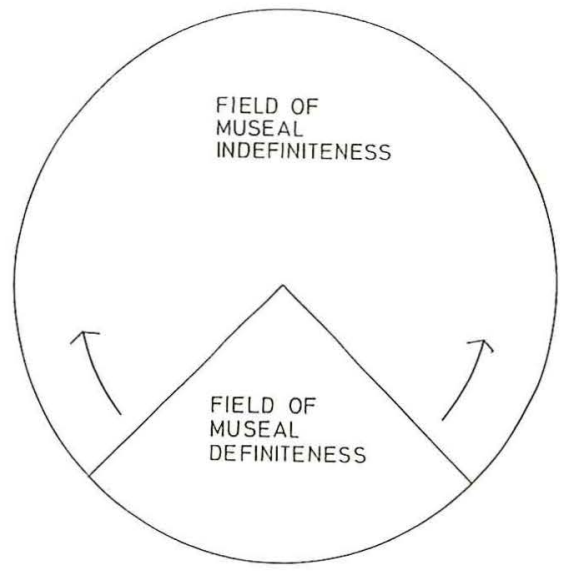

Fig. 1. Relation between fields of museum definiteness and museum indefiniteness.

objects we leave, but the amount of things which we call our heritage will proportionally lessen with the passing of time as the number of old things decreases in comparison with the number of more recent things. But our knowledge of our heritage will proportionally increase, for the disappearance of objects does not mean the disappearance of our knowledge and consciousness of them. The act of their attaining museality is in fact the beginning of salvation from forgetfulness. That is one of the primary functions of museums and the whole work of protection of the cultural and natural heritage.

\section{A WIDE RANGE OF POSSIBLE MEANINGS}

The subject of museology is research into the characteristics of objects or complexes of the cultural heritage which can, in an organized and oriented manner, transmit information from men to men and society, 
from one time to another time, within the framework of various contexts: primary, archeological and museum, and about the ways and the history of these ways of the organization and transmission of such information. The social, cultural, scientific, informational, technical and technological aspects of the working of these informational and communicative processes show the range of museological interest.

If we analyse the model of the communication process between man and an object of reality, a museum object, we shall see that in this process which is realized firstly between the museum's curator as user and the (potential) museum object as a document or emitter, we can follow the origin of information, which is subsequently the basis of selection, of almost all forms of the museum message. The process presupposes the existence of an object which emits a message with its broad field of museal indefiniteness (that is, with its wide range of possible meanings), as well as the interest of the museum curator who actively seeks to establish communication with the object. The curator must be able to perceive the content of the object through the signs which are inherent to the object as a sign vehicle. In other words, the object is a sign which appears in an infinite number of variants of meanings. The curator must know the language of the object to be able to understand its speech and to signify (decipher) its content and thus enlarge the quantity of human knowledge. To understand the object's speech, one needs to master those academic disciplines which deal with the object as a part of reality. In that context, the interdisciplinary linking of museology and other academic disciplines (such as art history for works of art, archaeology for artefacts and other archaeological findings, ethnology and anthropology for other objects of material culture, natural sciences for beings and objects of the natural world around us and objects of technical and technological culture as well, etc.) is necessary. By understanding the content of the object, reading it as a sum of signs, the curator actualizes the message of the object. The message, which need not have a wide range of meaning, is constituted in the contact between the object and the curator, and it causes a steady reduction of the object's field of indefiniteness, broadening the knowledge about it (Fig. 1). In actualizing the message, the curator makes use of scientific research methods. The response to the message created in the curator's mind represents information, because information about the object is the ultimate result of the communication process. Finally, the forming of information by the procedure of accurate articulation means the end of the process (Tudjman 1983 :43).

This communication process, which leads us to information, can be repeated on numerous occasions during the study and selection of an object. It is repeated also at higher levels of knowledge of the object. The result in the museum work is the constant decrease in the field of museal indefiniteness of each item of musealia and the enlargement of museal knowledge which is largely integrated or is identical with the knowledge within whatever scientific discipline has assisted us in the detailed study of the object.

We see that semiotic and information theories can be applied to museology. Comparing what has been said here with $\mathrm{B}$. Te- 


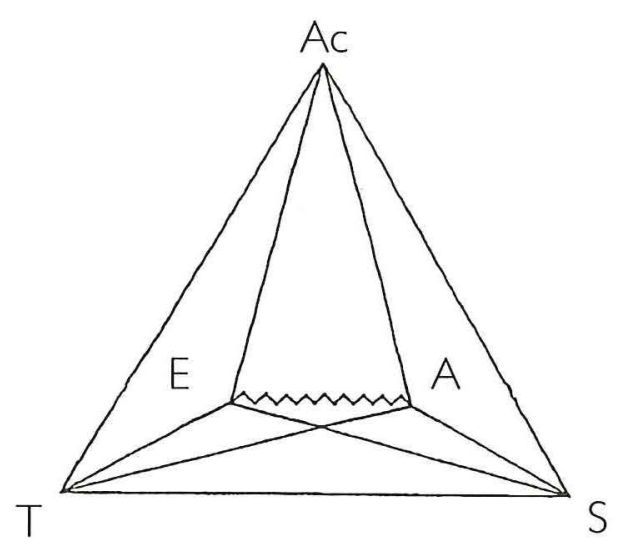

Fig. 2. Tezak's model of E-T-Ac-S-A complex. Information-documentation (INDOC) systems as the span between emission (E) and absorption (A) through, transmission (T), accumulation (Ac) and selection $(S)$ of information.

zak's E-T-Ac-S-A complex (Tezak 1969), which, using this structural model, defines information-documentation (INDOC) systems as the span between emission (E) and absorption (A) through, transmission (T), accumulation (Ac) and selection (S) of information (Fig. 2), we can see that the subject of museological theory and practice is the study of the absorption of data and information from the broad area of cultural and natural property and their emission by exhibiting, publishing and interpreting in situ, as well as the emission of messages which have been generated in their mutual relations. There is transmission (of information and messages), accumulation (making collective and documentation funds) and selection (separation from reality to meet various needs of classification or emission) between absorption and emission. So the museum activi- ty, and the interpretation of cultural and natural heritage in the wider sense, undoubtedly falls within the scope of specific IN-DOC systems which deal with sources of information as documents, the documentation about them, and with all levels of medial forms of transmission of objects and documentation about them. It shows at the same time that museology is fully integrated into the system of the information sciences.

\section{MUSEALIA AS DOCUMENTS IN TIME, SPACE AND SOCIETY}

The basic characteristic of cultural property is that it expresses, or testifies to, human existence, creativity or natural evolution. As musealia are cultural property and thus explicit communication objects, we can apply to them Tudjman's functional model (Tudjman 1983:72), which, applied to the museological discourse, links the structural and functional analysis of musealia. From Tudjman's model (Fig. 3) it is obvious that musealia are documents in time, as well messages in a certain space (naturally, when it is concretised) and information in a given society. Moreover, it shows that the documentation process, based on the material and physical structure of an object, takes place in time and space; the communication process, based on characteristic forms and elaboration of the material of an object, takes place in society and time; and the information process which (takes place always in the present), based on the content of an object, the museality, or on the knowledge about an object (where the physical presence of the object is sometimes not crucial), takes place in society and space. From 


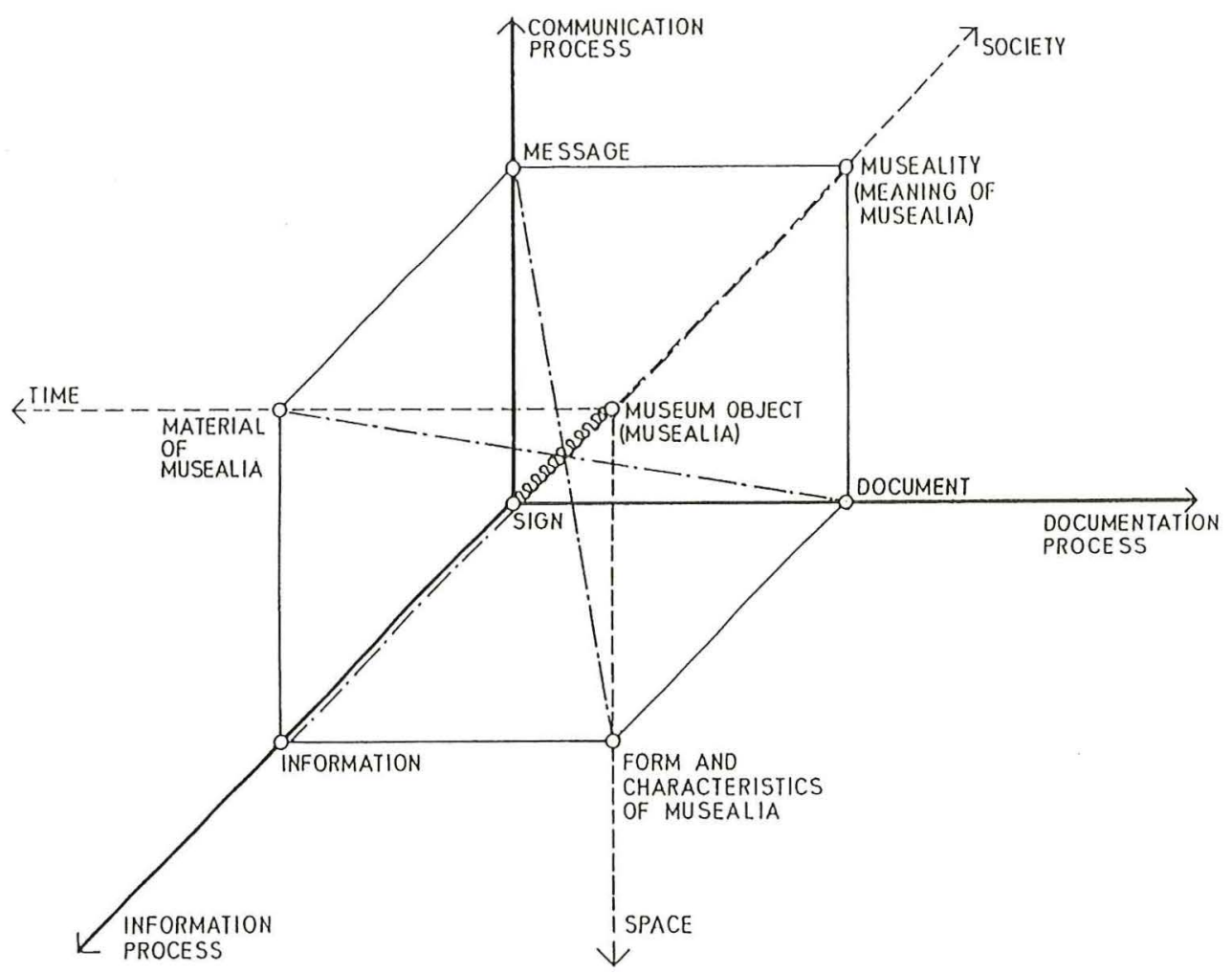

Fig. 3. Overlapping of structural and functional analyses of a museum object (modification according to M. Tudjman, 1983:72).

the model presented here we can see that the materiality of the museum object enters into the documentation process, its characteristics into the communication process, and its content (museality) into the information process.

If part of the subject of information science is the analysis of the social morphology of information, then this dimension of research should occupy a prominent place in museology, in which the social determination of the content and structure of the message is decisive (with the necessary scientific determination of the musealia) for the understanding of the heritage. Museology will act to orientate the total sphere of information science towards the field of cultural information. This is neglected in the present trend towards the pragmatic pressure of business and scientific information, which is limited by the simplicity of its selective deter- 


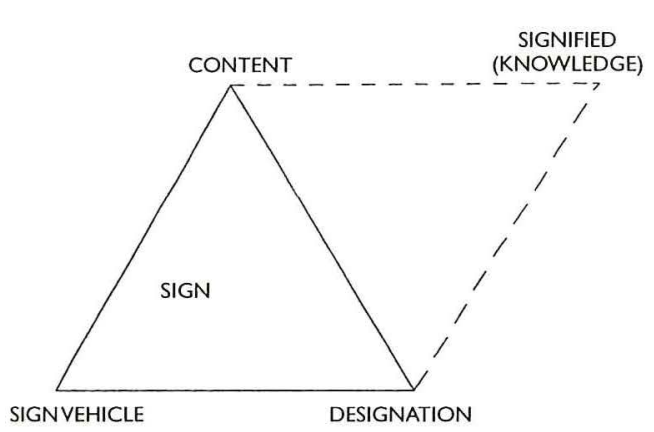

Fig. 4. Modification ofa semiotic sign model (according to Ch. Morris, from M. Tudman, 1983:33).

mination. Integration into the sphere of information science and application of theory modified according to the needs of museology will give museology considerably broader possibilities for acting, researching and applying appropriate scientific methods to its own subject.

Judged on this basis, the museum object (object of heritage) and its museological study form the basis of museology, while for other scientific disciplines it remains

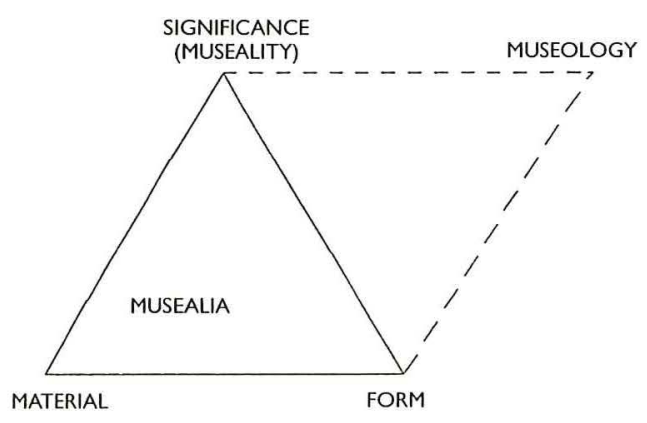

Fig. 5. Application of a semiotic sign model from Fig. 4 to museology. just one of the items of scientific interest. The museum object can be analyzed as a sign, so that by applying the basic determinants of the sign (sign vehicle, designation, the signified) to the museum object one can speak at the same time of three of its constituents which identify it (Fig. $4,5)$. These are the material, the form, and the meaning. It is precisely the unity of these three elements, with the meaning determining museality, which makes a real object the object of heritage and in certain circumstances the museum object. The material is fixed and is determined through certain research processes. The form, although a variable, is still sufficiently stable to allow certain messages to be communicated. But the meaning would be a variable which is in the process of continuous discovery and with which the basic features of the museum object, that is, its museality, are linked (Maroevic 1984:3).

The intertwining of museology with the basic academic disciplines in the study of the museum object with its complex meanings can be said to be motivated by the need to formulate knowledge. If we accept Tudjman's definition, that "knowledge is a physical substance organized in a way to contain information» (Tudjman 1986: 150 ), or a message which allows meaning to be transsmitted in the information process (Tudjman 1986:82), then we must conclude that this knowledge is what links museology with the basic scientific disciplines. It may be said that the knowledge produced in museums and in relation to heritage is the symbolic product of museology and of the basic academic disciplines (Maroevic 1993:231) (Fig. 6).

If knowledge and the need for it are 


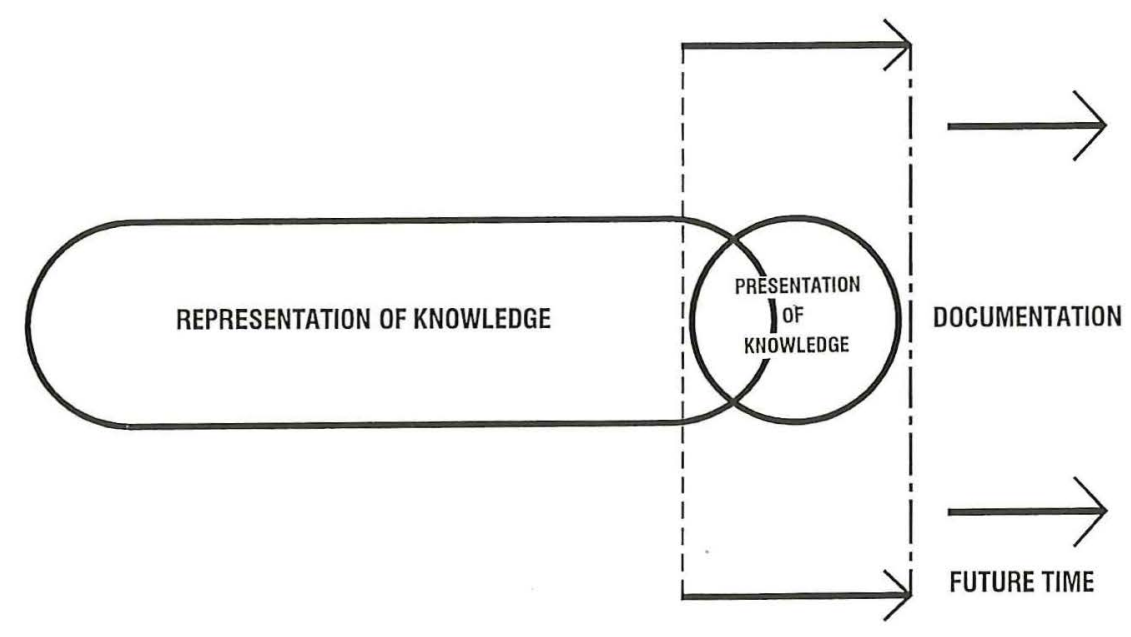

PAST TIME

PRESENT TIME

Fig. 6. Modified model of the representation of knowledge applied to museology (according to M. Tudjman, 1990:146).

understood as an impulse for the combining of several academic disciplines, the analysis can be taken further by saying that thinking is the primary process and creator of knowledge, whose structure comprises the following functions: cognition, communication, information, and memorization (Tudjman 1990:143). If we try to analyse these functions in their relationship to museology and the basic scientific disciplines, we see that the function of cognition aims at naming and understanding the objects, which in fact means that it participates in the formation of the totality of museum collections and in determining the meaning of individual objects within these funds or complexes. The communication function is concerned with the dissemination and distribution of knowledge, and in museums is as a rule performed through exhibitions, in which the imperative of the present time is always implied; the exhibition always takes place in the present time and may in this respect, in a way, be considered a form of presentation of new knowledge and a representation of knowledge accumulated and acquired in museums. The problem of the present time appears in the process and in the result of presenting cultural heritage too, where the existing knowledge about an object or complex is represented and the possibility of presentation of the knowledge generated in the context is opened. New knowledge is also generated in the individual contact of every human being, in his/her own way, with the objects of heritage. The information function is concerned with the organization and selection of knowledge. It is main- 
IVO MAROEVIC

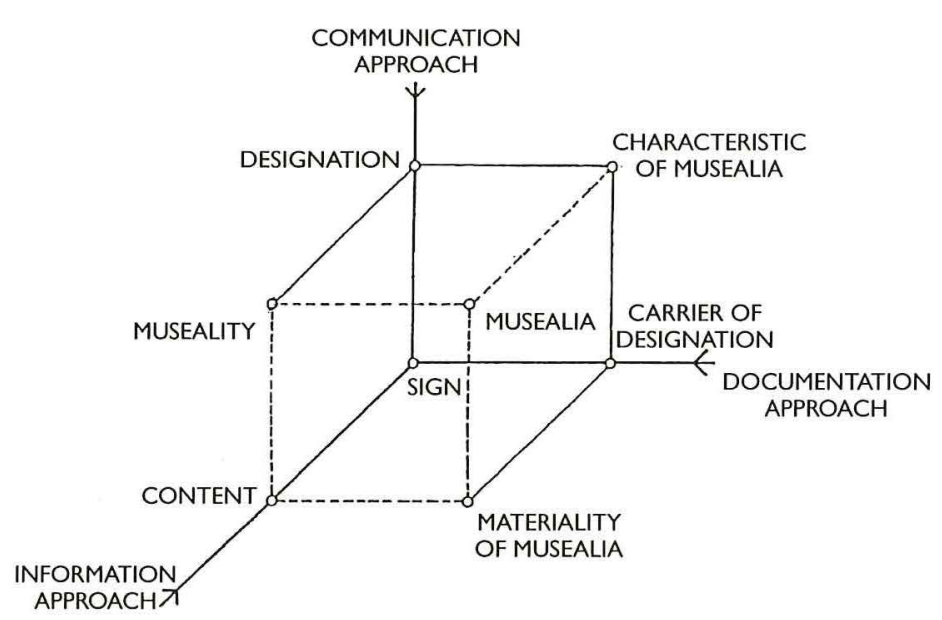

Fig. 7. Semiotic dimension of the INDOC object (according to M. Tudjman, 1983:40) - application to museology

ly directed towards the denotative elements within museum objects or complexes of heritage; it accumulates the entire knowledge produced in the museum and contained in museum objects or accumulated in heritage as well, and in this form its function can be interpreted as the representation of knowledge. And, finally, the function of memorization, which is expressed through the protection and storage of all elements of knowledge, manifests itself through the stability of the material and form. Naturally, protection and storage are most clearly expressed in the preservation of all of the characteristics of the objects and complexes of heritage, as well as of the entire documentation of recorded characteristics (Maroevic 1993:229.230).

\section{MUSEOLOGY AND THE BASIC} ACADEMIC DISCIPLINES

Looking once again, in this context, at the semiotic dimension of a museum object, or an object of heritage in general, and considering the analysis of three approaches to such a sign-object (Maroevic 1984:4), we can notice the relationship between museology and the basic academic disciplines. The documentation approach, directed to the carrier of the sign or materiality of the museum object is most closely linked to the basic academic discipline, so that through a modified scientific methodology it deals with immediate forms of reality as well as with the material and structure of each individual object. The communication approach deals with the designation, form or characteristics of objects and the importance of messages 
created in the communication process. This approach establishes a certain relationship between the basic academic discipline and museology. There are other layers of meaning here, not exclusively connected with the basic speech of the object's material. The information approach deals with the content or museality of the object and is almost exclusively oriented to the museological aspect. The results of the documentation-communication approach are discussed here on the level of museological significance, that is on the levels of those characteristics which make an individual object a museum object or an object of heritage (Fig. 7).

It could be said that the application of a variety of semiotic dimensions to heritage objects makes use mainly of analytical methods. This is the approach of the basic academic disciplines. They concentrate on the analysis of the object and its characteristics. Conversely, the museological approach, especially at the stage of interpretation and information emission through publications and exhibitions, tends to use the synthetic approach. This means using the analyses rich in scientific information to create special informationdocumentation systems which either were or should be synthetic by the nature of things. In that sense, the established relations between museology and the basic academic disciplines gain in importance, not only in museological practice, but also in education, training and the preparation of specialists, where the integration of both approaches is indispensable.

The museum object or object of heritage with all its physical and non-material qualities is an ideal link between these two opposing scientific approaches. The plura- lity of meanings of museum objects stimulates a more integrative approach, which broadens the interest in new forms of appearance of objects on the one hand, and in all the possibilities of interpretation and expression of their meaning on the other. On the whole, this enhances the integrity of the total human approach to the object, which saves it in some way and separates it from the exclusiveness of its meaning and importance only within one of the basic academic disciplines. Because of that, the meaning of an object of heritage or a museum object as a document of reality brings a new dimension to the entire analytic and synthetic procedure of studying reality.

\section{LITERATURE}

Maroevic, I.(1993): «Muzejska izlozba iskaz i prikaz znanja" (Museum exhibition presentation and representation of knowledge), In: Obrada jezika $i$ prikaz znanja, Ed. S. Tkalac, M. Tudjman, Zavod za informacijske studije, Zagreb, p. 227-237.

Maroevic, I. (1984): «Predmet muzeologije u okviru teorijske jezgre informacijskih znanosti» (Object of museology within the framework of the theoretical core of information sciences), Informatica Museologica, 1-3 (67-69): 3-5.

Stransky, Z. Z. (1970): "Pojam muzeologije» (The concept of museology), Muzeologija 8:2-39.

Sola, T. (1980): «Prezentacija predmeta u suvremenoj muzejskoj ustanovi» (Presentation of objects in the contemporary museum institution), Nase teme 251(5):641-649.

Tezak, B. (1969):

«Informaciono-dokumentaciono-komunikacioni (IN-DOK) sistem" (Information- 
IVO MAROEVIC

92 documentation-communication (IN-DOC) system), Informatologia Yugoslavica (1)1-4:1-11.

Tudjman, M. (1983): Struktura kulturne informacije (Structure of cultural information), Zavod za kulturu Hrvatske, Zagreb.

Tudjman, M. (1986): Teorija informacijske znanosti (Theory of information science),

Informator, Zagreb.

Tudjman, M. (1990): Obavijest i znanje

(Information and knowledge), Zavod za informacijske studije, Zagreb.

\section{NOTE}

Fragments from the author's book Introduction to Museology, Zavod za informacijske studije, Zagreb, 1993, compiled in August 1997 and arranged for publishing in Nordisk Museologi. Also presented June 211997 in the seminar Museums, society and museology, arranged by the Danish

Museumshojskolen, at Vester Vedsted on Jutland.

Ivo Maroeviç is Professor at the Departement of Information Science, University of Zagreb, Faculty of Philosophy.

Adr. I. Lucica 3, 10000 Zagreb, Croatia

Fax $+385-16156879$ 